\title{
Characterization of mRNA Profiles of Exosomes from Diverse Forms of M2 Macrophages
}

\author{
Yuan Yue $\mathbb{D}^{1},{ }^{1,2}$ Suiqing Huang $\mathbb{D}^{1},{ }^{1}$ Zixuan $W u\left(\mathbb{D},{ }^{3}\right.$ Keke Wang $\mathbb{D}^{1},{ }^{1}$ Huayang Li $\left(\mathbb{D},{ }^{1}\right.$ \\ Jian Hou $\mathbb{D}$, ${ }^{1}$ Xiaolin Huang $\left.\mathbb{D}\right)^{1}$ Li Luo $\mathbb{D}^{1},{ }^{1}$ Quan Liu $\mathbb{D}^{1},{ }^{1}$ and Zhongkai Wu $\mathbb{D}^{1,2}$ \\ ${ }^{1}$ Department of Cardiac Surgery, The First Affiliated Hospital of Sun Yat-sen University, China \\ ${ }^{2}$ NHC Key Laboratory of Assisted Circulation, Sun Yat-sen University, China \\ ${ }^{3}$ Organ Transplant Center, The First Affiliated Hospital of Sun Yat-sen University, China
}

Correspondence should be addressed to Zhongkai Wu; wuzhk@mail.sysu.edu.cn

Received 5 July 2020; Revised 9 November 2020; Accepted 12 November 2020; Published 23 November 2020

Academic Editor: A. Ortega

Copyright (c) 2020 Yuan Yue et al. This is an open access article distributed under the Creative Commons Attribution License, which permits unrestricted use, distribution, and reproduction in any medium, provided the original work is properly cited.

\begin{abstract}
Exosomes transmit certain amounts of molecules to specific recipient cells for intercellular communication. Among these molecules, messenger RNAs (mRNAs) may be delivered and translated into proteins in the recipient cells, and these mRNAs are thought to be critical mediators of exosomal functions. There are three subtypes of $M 2$ macrophages $\left(M_{2} \Phi\right), M_{2 a} \Phi, M_{2 b} \Phi$, and $\mathrm{M}_{2 \mathrm{c}} \Phi$, which have different specific functional programs. The aim of the present study was to screen the mRNA profiles in the exosomes of these macrophage subtypes and to analyze the transcriptomic profile features associated with their specific functions. The mRNA contents of the exosomes isolated from the culture supernatants of the $\mathrm{M}_{2} \Phi$ subtypes were analyzed and compared using the Illumina HiSeq platform. The results indicated that the exosomes contained particular mRNAs from their source cells and were messengers of cellular functions. Bioinformatics analysis suggested that the exosomal $\mathrm{mRNAs}_{\mathrm{s}}$ from $\mathrm{M}_{2 \mathrm{~b}} \Phi \mathrm{s}$ are enriched in the Toll-like receptor (TLR), tumor necrosis factor (TNF), NOD-like receptor (NLR), and NF-kappa B (NF- $\kappa$ B) signaling pathways. The mRNA profile of exosomes from $\mathrm{M}_{2 \mathrm{~b}} \Phi$ was distinctly different from that of exosomes from $\mathrm{M}_{2 \mathrm{a}} \Phi$ and $\mathrm{M}_{2 \mathrm{c}} \Phi$ and was consistent with the $\mathrm{M}_{2 \mathrm{~b}} \Phi$ cytological characteristic of maintaining a high level of proinflammatory cytokine and regulatory factor production. Therefore, the mRNA profiles revealed several characteristics of the exosomes from diverse forms of $\mathrm{M}_{2} \Phi$. Further functional investigations based on these results may advance the understanding of the physiological roles of exosome-transferred mRNAs in M $\Phi$ functions.
\end{abstract}

\section{Introduction}

Exosomes are small membrane-derived vesicles of endocytic origin that are secreted by most cells and are approximately $40-200 \mathrm{~nm}$ in diameter [1]. Exosomes are extracellular phospholipid nanocarriers that function as signalosomes and transmit molecules (DNA, RNA, proteins, and lipids) to specific recipient cells for intercellular communication $[2,3]$. Among the molecules contained in exosomes, messenger RNAs (mRNAs) may be delivered and translated into proteins in recipient cells [3, 4]. Valadi et al. [3] first reported that exosomes mediate the transfer of mRNAs and demonstrated that exosomes are capable of shuttling mRNAs between mast cells. In addition, Zomer et al. [5] reported that exosomes are able to deliver the mRNA encoding Cre recom- binase to recipient cells to perform Cre-LoxP-mediated recombination. Therefore, mRNAs are thought to be critical mediators of exosomal functions.

Macrophages (MФs) are frontier soldiers of the innate immune system, which is mainly composed of epithelial cells, phagocytes, and natural killer (NK) cells $[6,7]$. MФs are also widely distributed immune cells that have an indispensable role in pathogen elimination, tissue development, and wound repair [8]. MФs have a high degree of plasticity and may be polarized by the microenvironment to mount specific functional programs. Polarized MФs may be classified into two subtypes: classically activated macrophages $\left(M_{1} \Phi s\right)$ and alternatively activated macrophages $\left(\mathrm{M}_{2} \Phi s\right)$ [9]. $\mathrm{M}_{1} \Phi s$, also called proinflammatory macrophages, are induced by Th1 cytokines or by lipopolysaccharide (LPS) recognition and 
TABle 1: Primer sequences used for RT-PCR.

\begin{tabular}{lcc}
\hline Gene $($ rat $)$ & Forward & Reverse \\
\hline GAPDH & GGTCATCCATGACAACTT & GGGGCCATCCACAGTCTT \\
CCL17 & AGTGCTGCCTGGACTACTTC & CTGGACAGTCTCAAACACGATGG \\
CCL1 & GAGCCTGCAGTTTCACTCA & GATCTGTGAGCCTGCATCAGT \\
CXCL13 & ACATGCCTAGACTGAGAGCT & AAGGCAGATGGCCAGTAGAAG \\
\hline
\end{tabular}

CCL: C-C motif chemokine ligand; CXCL: C-X-C motif chemokine ligand.

release high levels of proinflammatory cytokines $[10,11]$. $M_{1} \Phi s$ participate in the removal of pathogens, debris clearance, and neovascularization [12]. $\mathrm{M}_{2} \Phi \mathrm{s}$, named antiinflammatory macrophages, are polarized by Th2 cytokines and characterized by high levels of anti-inflammatory cytokines and profibrogenic factors $[12,13] . \mathrm{M}_{2} \Phi$ s may be further subdivided into $\mathrm{M}_{2 \mathrm{a}} \Phi$ s (stimulated by interleukin(IL-) 4 and IL-13), $\mathrm{M}_{2 \mathrm{~b}}$ Фs (stimulated by immune complexes (IC) in combination with lipopolysaccharide (LPS)), and $\mathrm{M}_{2 \mathrm{c}}$ Фs (stimulated by IL-10, 13, and 14). Although these three phenotypes are all classified as $\mathrm{M}_{2} \Phi s$, they have distinctly different characteristics. $\mathrm{M}_{2 \mathrm{a}} \Phi$ s, also named woundhealing macrophages, mainly secrete profibrotic factors, such as transforming growth factor- $\beta$ (TGF- $\beta$ ), to contribute to tissue repair [15]. $\mathrm{M}_{2 \mathrm{c}}$ Фs exhibit robust anti-inflammatory activities by releasing large amounts of IL-10 and profibrotic activity by secreting high levels of TGF- $\beta$ [16]. $\mathrm{M}_{2 \mathrm{~b}} \Phi \mathrm{s}$, also known as regulatory macrophages, express both proinflammatory and anti-inflammatory cytokines (IL- $1 \beta$, IL-6, tumor necrosis factor- (TNF-) $\alpha$, and IL-10) and regulate the immune response and inflammatory reaction $[14,17,18]$. Furthermore, it was previously reported by our group that $\mathrm{M}_{2 \mathrm{~b}} \Phi$ s are able to reduce the activation of cardiac fibroblasts, which is different from the profibrotic actions of $\mathrm{M}_{2 \mathrm{a}} \Phi \mathrm{s}$ and $\mathrm{M}_{2 \mathrm{c}}$ Фs [19].

Exosomes are able to deliver mRNAs encoding certain crucial proteins to recipient cells, and exosomes from forms of $\mathrm{M}_{2} \Phi s$ may partly explain their specific functions. In the present study, the characteristics of the transcriptomic profiles of mRNAs contained in exosomes from polarized $\mathrm{M}_{2} \Phi s$ were evaluated. Microarray and bioinformatics approaches were utilized to identify specific genes and to analyze the mRNA expression features. The present study provided one solution for studying how macrophages influence the downstream cells and provide a foundation for further exploring the function of macrophage phenotypes.

\section{Materials and Methods}

2.1. Animals. A total of 20 Sprague-Dawley (SD) rats (6-8 weeks, weight 200-250 g) were obtained from Beijing Vital River Laboratory Animal Technology Co., Ltd. All of the animals were allowed free access to food and water and were housed under a constant temperature $\left(22 \pm 2^{\circ} \mathrm{C}\right)$ and humidity $(45 \pm 5 \%)$ and a $12 \mathrm{~h} \mathrm{light/dark} \mathrm{cycle.} \mathrm{All} \mathrm{of} \mathrm{the} \mathrm{animal}$ procedures were approved by the Institutional Animal Care Committee of Sun Yat-sen University and conformed to the Guide for the Care and Use of Laboratory Animals by the US National Institute of Health (NIH).
2.2. Isolation and Polarization of $M \Phi$ s. The rats that were used to harvest the MФs were sacrificed by dislocation of the cervical vertebrae. Bone marrow was collected from the tibias and femurs, washed with complete Roswell Park Memorial Institute- (RPMI-) 1640 medium (Gibco, Thermo Fisher Scientific, Waltham, MA, USA), and centrifuged at $500 \mathrm{x} \mathrm{g}$ for $5 \mathrm{~min}$. The cells were then cultured in flasks (Corning, NY, USA) at $37^{\circ} \mathrm{C}$ in a $5 \% \mathrm{CO}_{2}$ incubator in RPMI-1640 for the first 3 days and then in Dulbecco's modified Eagle's medium (DMEM; Gibco) for the next 3 days to generate mature bone marrow-derived macrophages (BMDMs). Both the RPMI-1640 and DMEM were supplemented with $10 \%$ fetal bovine serum (FBS; Gibco) and $10 \mathrm{ng} / \mathrm{ml}$ macrophage colony-stimulating factor (MCSF; PeproTech, Rocky Hill, NJ, USA). On day 6, the BMDMs were replated in 24-well plates (Corning) to differentiate into $\mathrm{M}_{1} \Phi \mathrm{s}$ with the addition of $1 \mu \mathrm{g} / \mathrm{ml}$ LPS (Sigma-Aldrich, St. Louis, MO, USA), into $\mathrm{M}_{2 \mathrm{a}}$ Фs with $20 \mathrm{ng} / \mathrm{ml}$ IL-4 (PeproTech) and $20 \mathrm{ng} / \mathrm{ml} \mathrm{IL-13} \mathrm{(PeproTech),} \mathrm{into} \mathrm{M}_{2 \mathrm{~b}}$ Фs with $50 \mu \mathrm{g} / \mathrm{ml} \mathrm{IgG} \mathrm{(Sigma-Aldrich)} \mathrm{and} 100 \mathrm{ng} / \mathrm{ml}$ LPS (SigmaAldrich), or into $\mathrm{M}_{2 \mathrm{c}}$ Фs with $20 \mathrm{ng} / \mathrm{ml}$ IL-10 (PeproTech) [20-23]. After incubation for $24 \mathrm{~h}$, the cells were harvested for marker analysis or the cells were replated and cultured with fresh FBS-free DMEM without stimulation for another $24 \mathrm{~h}$. Subsequently, the cell-free supernatants were collected at $24 \mathrm{~h}$ for harvesting of exosomes.

2.3. Identification of $M \Phi s$ by Flow Cytometry and Reverse Transcription-Quantitative PCR (RT-qPCR). The BMDMs were harvested and prepared as single-cell suspensions after 5 min of digestion by $0.25 \%$ trypsin (Gibco) at $37^{\circ} \mathrm{C}$. Subsequently, the purified cells were stained with APC-Cy7conjugated anti-rat CD45 antibody (cat. no. 561588; BD Biosciences, San Jose, CA, USA) and FITC-conjugated anti-rat CD68 antibody (cat. no. MA5-28262; Invitrogen, Carlsbad, CA, USA) or stained with isotype control (cat. no. 557873, BD Biosciences and cat. no. 11-4714-81, Invitrogen). Flow cytometry was performed using a Beckman CytoFLEX Flow Cytometer (Beckman Coulter, Miami, FL, USA), and the results were analyzed with FlowJo software (FlowJo, Ashland, OR, USA). The total RNA of the cells was extracted using TRIzol reagent (Invitrogen), and complementary (c) DNA was synthesized using the qPCR RT Master Mix kit (TOYOBO, Osaka, Japan). PCR primers were designed and synthesized by Invitrogen (Thermo Fisher Scientific). qPCR analysis was performed according to the manufacturer's protocols using the KOD SYBR qPCR Mix (TOYOBO) in a LightCycler 480 (Roche, Basel, Switzerland). For analysis, the expression of target genes was normalized to that of 


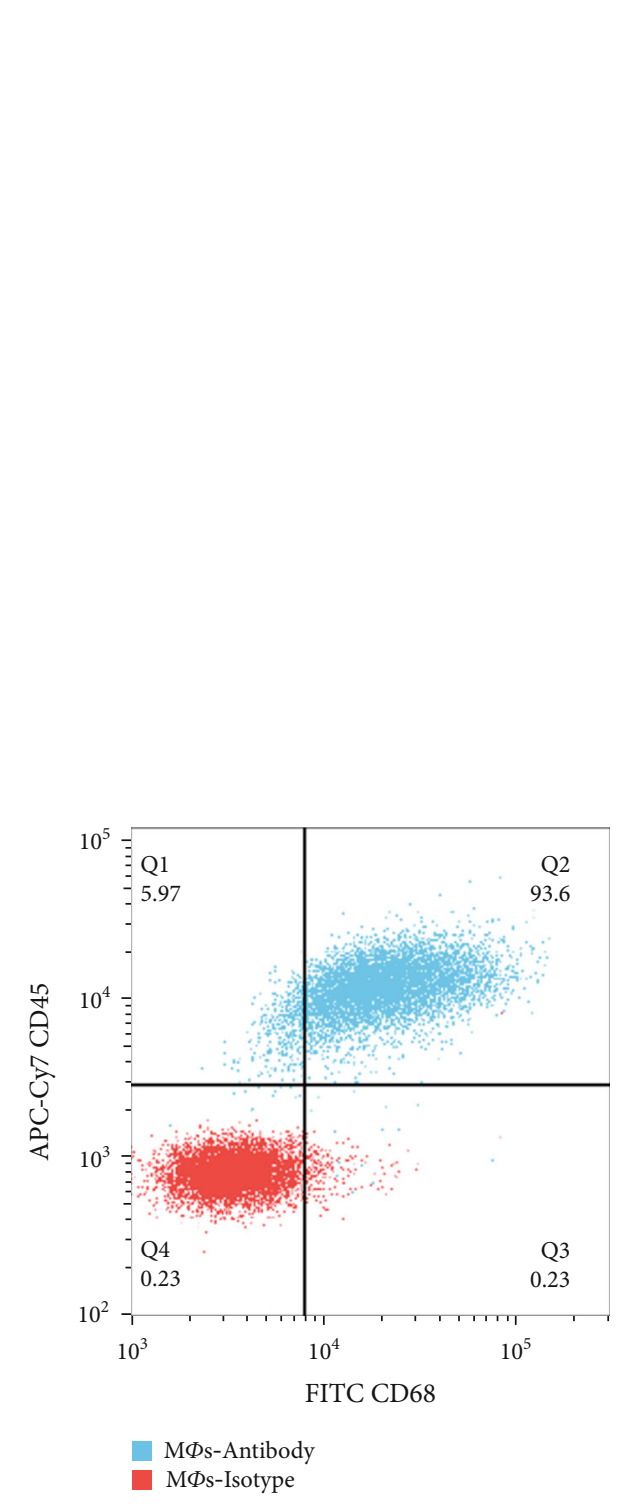

(a)

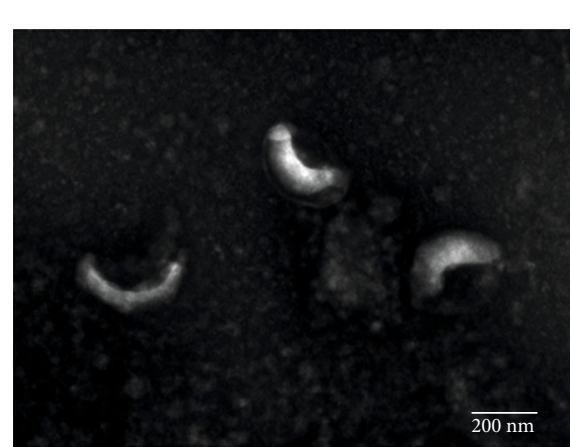

(c)
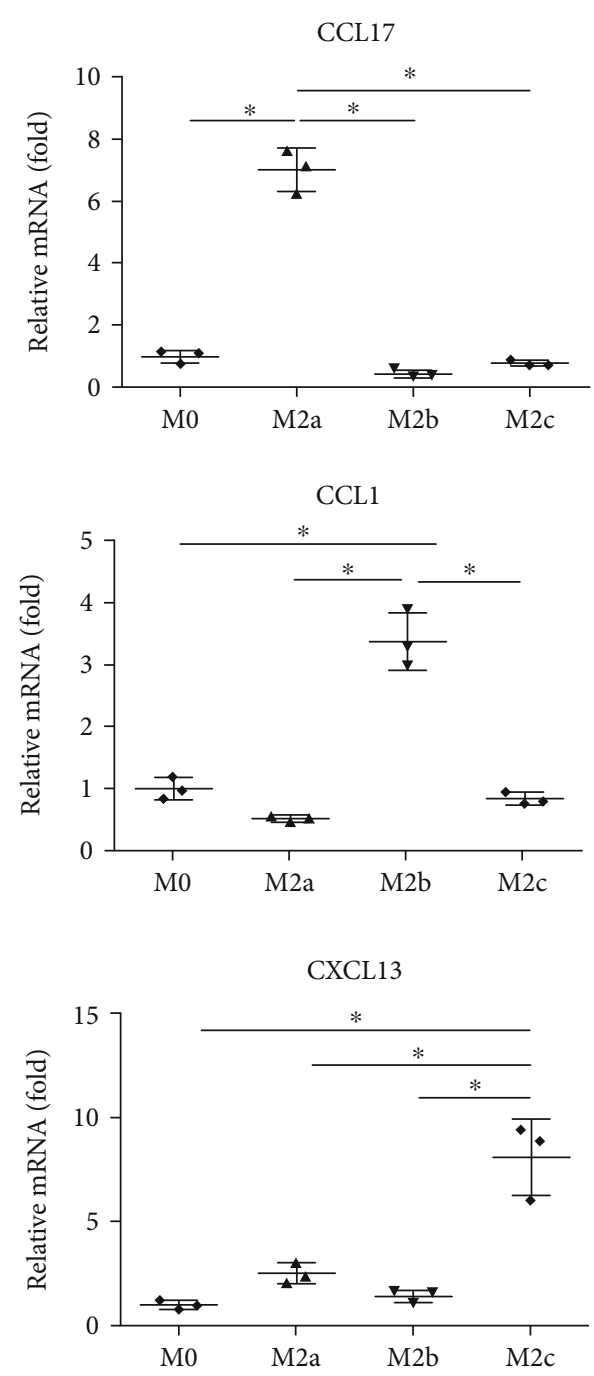

(b)

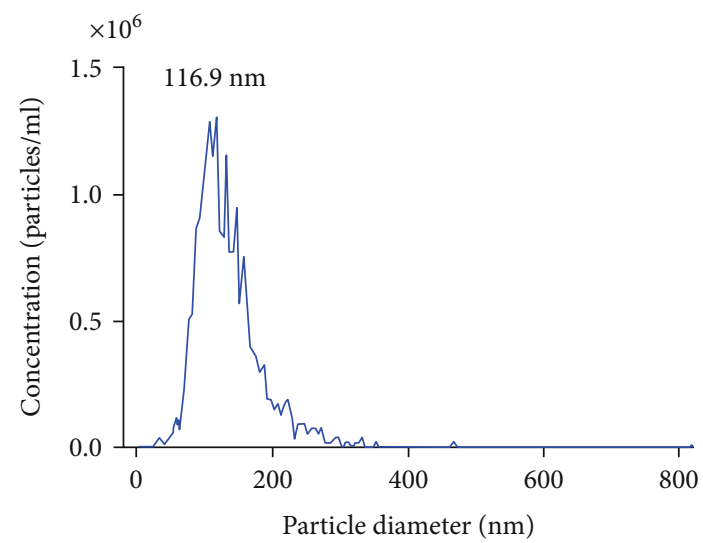

(d)

FIgURe 1: Continued. 


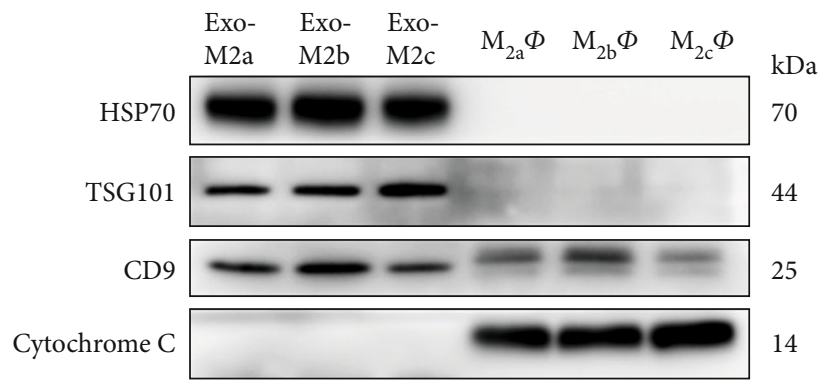

(e)

Figure 1: Identification of $\mathrm{M}_{2} \Phi$ s and exosomes. (a) Procedure for the identification of BMDMs positive for CD45 and CD68 by flow cytometry. (b) Gene expression profiles of the different $\mathrm{M}_{2} \Phi$ phenotypes measured by reverse transcription-quantitative PCR. $M_{2 a} \Phi s$, $\mathrm{M}_{2 \mathrm{~b}} \Phi \mathrm{s}$, and $\mathrm{M}_{2 \mathrm{c}} \Phi \mathrm{s}$ expressed high levels of CCL17, CCL1, and CXCL13, respectively. Data are presented as fold changes relative to the expression levels in untreated BMDMs and are the mean of three independent experiments. ${ }^{*} P<0.05$. (c) Representative transmission electron microscopy image of exosomes (scale bar, $200 \mathrm{~nm}$ ). (d) The size and concentration of exosomes measured by qNano analysis. (e) Western blot analysis of exosome marker proteins and negative protein. BMDM: bone marrow-derived macrophage; CCL: C-C motif chemokine ligand; CXCL: C-X-C motif chemokine ligand.

GAPDH. The primer sequences for the target genes are illustrated in Table 1.

\subsection{Isolation of Exosomes from the $M \Phi$ Culture Supernatants.} The culture supernatants containing exosomes were centrifuged at $2,000 \mathrm{x} \mathrm{g}$ and $4^{\circ} \mathrm{C}$ for $10 \mathrm{~min}$ to remove the cells and debris. Subsequently, the exosomes were extracted and collected from the culture supernatants with an exoEasy Maxi Kit (Qiagen GmbH, Hilden, Germany) according to the manufacturer's protocol. In short, the exoEasy Maxi Kit uses a membrane-based affinity binding step to isolate exosomes from cell culture supernatants. The method does not distinguish exosomes by size or cellular origin and is not dependent on the presence of a particular epitope. Instead, it makes use of a generic, biochemical feature of exosomes to recover the entire spectrum of exosomes present in samples. Particulate matter other than exosomes, like larger protein complexes, is largely removed during the binding and ensuing wash step. After washing the column membrane, intact exosomes are eluted in an aqueous buffer containing primarily inorganic salts and are then ready to use for the subsequent analysis.

\subsection{Transmission Electron Microscopy Observations and} qNano Analysis of Exosomes. The exosome samples were added to the copper mesh and precipitated for $3 \mathrm{~min}$. Phosphotungstic acid was used for negative staining. Finally, the mesh was observed with a transmission electron microscope (JEM-1200EX; JEOL, Tokyo, Japan). The sizes and concentrations of the exosomes were determined using qNano analysis (Izon Science, Burnside, Christchurch, New Zealand) based on the manufacturer's instructions.

2.6. Western Blot Analysis. The total protein from the cells and exosomes was lysed using RIPA lysis buffer (Beyotime Biotechnology, Shanghai, China). The protein concentrations were measured with a Bio-Rad Protein Assay Kit (Bio-Rad Laboratories, CA, USA). The proteins were fractionated by $8-15 \%$ sodium dodecyl sulfate-polyacrylamide gels (SDS-PAGE) and transferred to polyvinylidene fluoride
(PVDF) membranes (Millipore, Billerica, MA, USA). The membranes were blocked and then incubated with antibodies against CD9 (cat. no. ab92726; Abcam, Cambridge, MA, USA), heat shock protein (HSP) 70 (cat. no. 66183-1; Proteintech Group, Wuhan, China), tumor susceptibility gene 101 (TSG101; cat. no. ab133586; Abcam), and cytochrome C (cat. no. ab13575; Abcam). Subsequently, the membranes were incubated with a horseradish peroxidase-conjugated secondary antibody (Thermo Fisher Scientific) at room temperature for $1 \mathrm{~h}$ and were visualized using enhanced chemiluminescence reagents (Millipore) according to the manufacturer's instructions.

2.7. Exosomal RNA Extraction and $m R N A$ Sequencing (mRNA-seq) Library Preparation. The total exosomal RNA was extracted using the exoRNeasy Serum/Plasma Maxi Kit (Qiagen $\mathrm{GmbH}$ ) according to the manufacturer's protocol and used for mRNA sequencing. RNA quantification was performed with Qubit 3.0 (Thermo Fisher Scientific). For mRNA-seq, library preparation was performed using the $\mathrm{Epi}^{\mathrm{TM}}$ longRNA Ampli kit (Epibiotek, Guangzhou, China) according to the manufacturer's instructions. In brief, the ribosomal RNA (rRNA) was depleted and the RNA samples were mixed with the provided RT Primer mix and deoxynucleoside triphosphate (dNTP) mix to perform RT and synthesize the first-strand cDNA by PCR. After RT, the second-strand CDNA was synthesized by PCR under optimized reaction conditions. After amplification by PCR, cDNA was purified and size-selected with magnetic beads. Library evaluation and quantification were performed on a Qseq100 Bio-Fragment Analyzer (BiOptic, Taiwan, China), and subsequent next-generation sequencing (NGS) was performed by using an Illumina HiSeq X Ten System (Illumina, San Diego, CA, USA).

2.8. Bioinformatics Analysis of the mRNA-seq Data. In brief, adaptor and primer sequences from the library were trimmed. After trimming, the sequence reads were then aligned to the rat genome (version Rnor_6.0) using Hisat2, followed by a postalignment quality check to assess the 


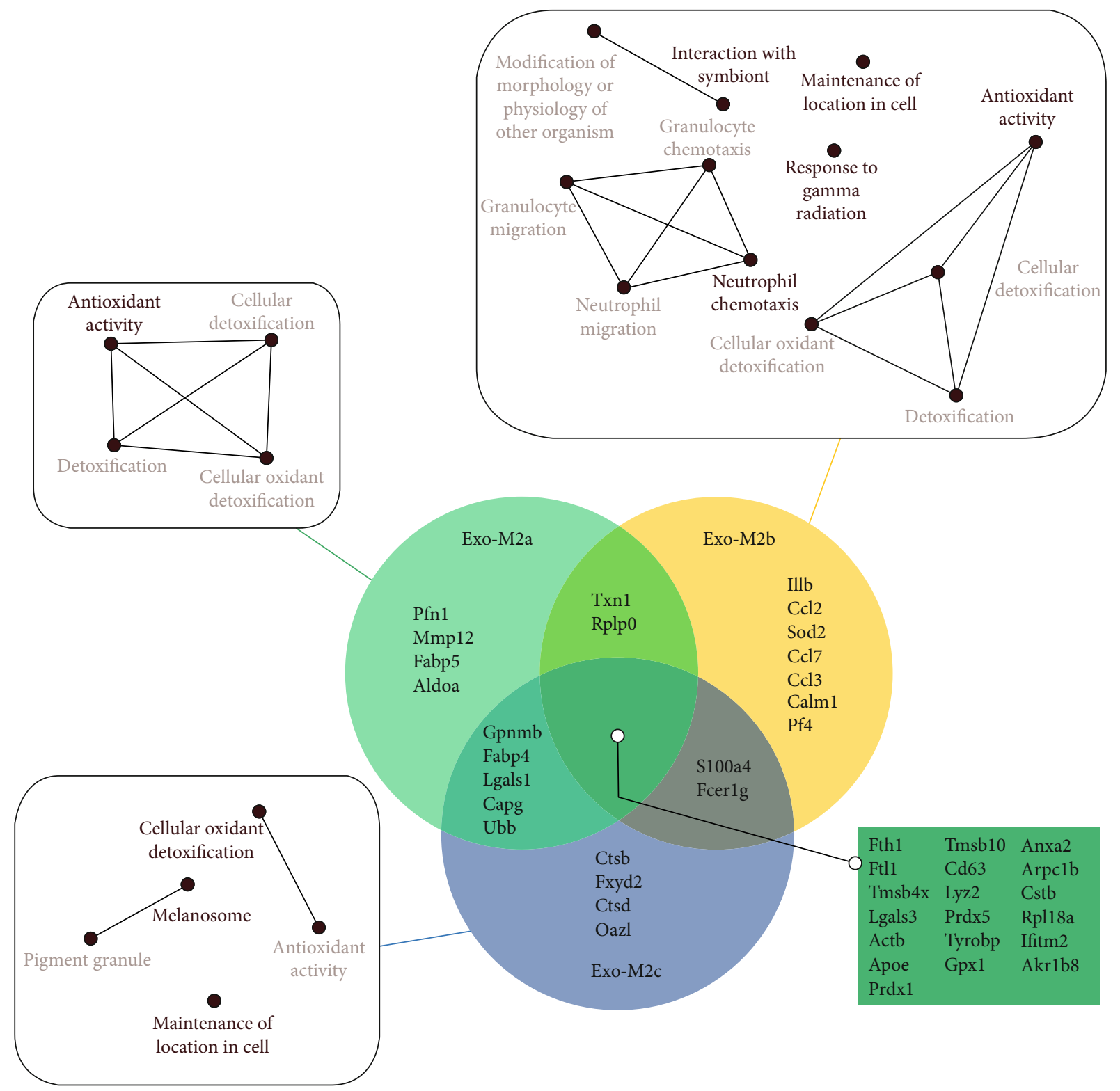

Figure 2: Top 30 most abundant mRNAs in exosomes from different $\mathrm{M}_{2} \Phi$ s and the pathway networks. The top 30 mRNAs in the exosomes are presented in the Venn diagram. The GO pathway networks of the mRNAs were categorized using CluePedia. The threshold for the network analysis was set to $P<0.05$ and FDR $<0.05$. GO: Gene Ontology; FDR: false discovery rate.

performance of the alignment. After the alignment, HTseq was used to determine the counts of the reads mapped to the genome. Reads per kilobase per million mapped reads (RPKM) was used to standardize the expression data, which allowed for the comparison of expression levels between mRNAs. Using the DESeq2 algorithm, mRNAs of different abundances were identified by fold change ( $>2$-fold) and significance level $(P<0.05)$ filtering. Volcano plots were drawn using $\mathrm{R}$ based on the differential mRNA analysis, and the color was determined based on the filtering criteria. Networks of these mRNAs were algorithmically generated based on the potential connectivity of their products using the Database for Annotation Visualization and Integrated Discovery online database (DAVID; version 6.8; http://david. http://ncifcrf.gov) [24, 25] and Cytoscape (version 3.6.1)
[26], which is an open-source bioinformatics software platform for visualizing molecular interaction networks. Enrichment analysis, including Gene Ontology (GO) functional analysis and Kyoto Encyclopedia of Genes and Genomes (KEGG) pathway analysis, was performed using DAVID. Furthermore, the plug-in ClueGO (version 2.5.5) of Cytoscape was used to search for potential associated pathways of specific genes [27].

2.9. Statistical Analysis. Statistically significant differences between groups were assessed by one-way analysis of variance (ANOVA) followed by Bonferroni's post hoc test. $P<$ 0.05 was considered to indicate statistical significance. Statistical tests were performed using GraphPad Prism Software (Version X; GraphPad, La Jolla, CA, USA). 
TABLE 2: Unique mRNAs in exosomes of different group.

\begin{tabular}{|c|c|}
\hline Symbol & Description \\
\hline \multicolumn{2}{|c|}{ Unique mRNAs in Exo-M2a } \\
\hline Alpk2 & Alpha-kinase 2 \\
\hline$C d 55$ & $\begin{array}{l}\text { CD55 molecule, decay-accelerating } \\
\text { factor for complement }\end{array}$ \\
\hline Cnksr 1 & $\begin{array}{c}\text { Connector enhancer of kinase } \\
\text { suppressor of Ras } 1\end{array}$ \\
\hline Dmd & Dystrophin \\
\hline Dok5 & Docking protein 5 \\
\hline$E d n 1$ & Endothelin 1 \\
\hline Fam26d & $\begin{array}{l}\text { Family with sequence similarity } 26 \text {, } \\
\text { member D }\end{array}$ \\
\hline Hey1 & $\begin{array}{l}\text { hes-related family bHLH transcription } \\
\text { factor with YRPW motif } 1\end{array}$ \\
\hline LOC103690049 & Deoxyribonuclease gamma-like \\
\hline Maob & Monoamine oxidase B \\
\hline Timd2 & $\begin{array}{l}\text { T-cell immunoglobulin and mucin } \\
\text { domain containing } 2\end{array}$ \\
\hline Хрпрер2 & X-prolyl aminopeptidase 2 \\
\hline \multicolumn{2}{|c|}{ Unique mRNAs in Exo-M2b } \\
\hline Cdo1 & Cysteine dioxygenase type 1 \\
\hline Gcnt2 & $\begin{array}{l}\text { Glucosaminyl (N-acetyl) transferase 2, } \\
\text { I-branching enzyme }\end{array}$ \\
\hline Gpr84 & G protein-coupled receptor 84 \\
\hline Il2ra & Interleukin 2 receptor subunit alpha \\
\hline LOC102550416 & Small proline-rich protein 2I-like \\
\hline LOC103692265 & Killer cell lectin-like receptor 4 \\
\hline LOC103692615 & Uncharacterized LOC103692615 \\
\hline LOC689205 & Similar to cytoplasmic beta-actin \\
\hline Nrarp & Notch-regulated ankyrin repeat protein \\
\hline Podnl1 & Podocan-like 1 \\
\hline Ptgs 2 & Prostaglandin-endoperoxide synthase 2 \\
\hline Serpinb6b & $\begin{array}{l}\text { Serine (or cysteine) peptidase inhibitor, } \\
\text { clade } B \text {, member } 6 b\end{array}$ \\
\hline Snhg4 & $\begin{array}{l}\text { Small nucleolar RNA host gene } 4 \\
\text { (nonprotein coding) }\end{array}$ \\
\hline \multicolumn{2}{|c|}{ Unique mRNA in Exo-M2c } \\
\hline Slc35g1 & Solute carrier family 35 , member G1 \\
\hline
\end{tabular}

\section{Results}

3.1. Identification of Different Subtypes of $M_{2} \Phi$. Following the specific treatments of the BMDMs, they were stained and analyzed by flow cytometry to quantify the cells with the expression of CD45 (APC-Cy7) and CD68 (FITC), which are markers for MФs. The results indicated that the bone marrow cells had differentiated into MФs (Figure 1(a)). Subsequently, the phenotypes of the polarized BMDMs were identified based on their gene expression using qPCR. $\mathrm{M}_{2 \mathrm{a}} \Phi s, \mathrm{M}_{2 \mathrm{~b}} \Phi s$, and $\mathrm{M}_{2 \mathrm{c}}$ Фs expressed high levels of C-C motif chemokine ligand (CCL) 17, CCL1, and C-X-C motif chemokine ligand (CXCL) 13, respectively (Figure 1(b)). Col- lectively, these results indicated that BMDMs were successfully polarized into different $\mathrm{M}_{2} \Phi$ subtypes.

\subsection{Validation of the Exosomes Isolated from the Cell Culture} Supernatants. Exosomes were extracted and collected from the cell supernatants with an exoEasy Maxi Kit (Qiagen $\mathrm{GmbH}$ ). The exosomes were identified using an electron microscope, and they exhibited typical vesicle-like structures and diameters of approximately 100-200 nm (Figure 1(c)). The qNano analysis technique was used to measure the size and concentration of the exosomes (Figure 1(d)). The results indicated that the diameter was $30-400 \mathrm{~nm}$ (median, $116.9 \mathrm{~nm}$ ). By using western blot analysis, well-known exosomal maker proteins, TSG101, HSP70, and CD9, were detected in exosomes, but not in $\mathrm{M}_{2} \Phi$ cells. On the other hand, cytochrome $\mathrm{C}$ was detected in $\mathrm{M}_{2} \Phi$ cells, but it was absent from the exosomes, indicating that the exosomes were not contaminated with apoptotic bodies or cell debris (Figure 1(e)). These data indicated that exosomes were acquired from the supernatants with good purity.

3.3. An Overview of the $m R N A$-seq Results. For clarity, the exosomes from $\mathrm{M}_{2 \mathrm{a}} \Phi s, \mathrm{M}_{2 \mathrm{~b}} \Phi s$, and $\mathrm{M}_{2 \mathrm{c}} \Phi s$ were abbreviated as Exo-M2a, Exo-M2b, and Exo-M2c, respectively. The top 30 mRNAs in the exosomes are presented in a Venn diagram in Figure 2. Fth1, Ftl1, and Tmsb4x were the 3 most abundant transcripts in all of the groups. The other highly abundant mRNAs in all the groups were Lgals3, Actb, Apoe, Prdx1, Tmsb10, and Lyz2. The results indicated that numerous transcripts are abundant in the exosomes from all three phenotypes, while the transcript of Illb, which encodes IL$1 \beta$, was preferentially detected in Exo-M2b and was less abundant in Exo-M2a and Exo-M2c. There were other cytokine- and chemokine- associated transcripts that were highly expressed in Exo-M2b but not in Exo-M2a and Exo-M2c; these transcripts included CCL2, CCL7, CCL3, and Pf4. These mRNAs were then categorized into GO pathway networks according to molecular function using CluePedia (Figure 2).

3.4. Unique $m R N A$ s Contained in the Exosomes. By analyzing the mRNA profiles of the exosomes, it was revealed that certain mRNAs were detectable in the exosomes from a particular phenotype but barely detectable in the exosomes from the other phenotypes. To identify transcripts unique to these phenotypes, criteria of $m R N A s$ were detected in one group with an RPKM value of $>5$ and not detected in other groups $(\mathrm{RPKM}<0.1)$. With these criteria, 12, 13, and 1 mRNAs were identified as unique transcripts in Exo-M2a, Exo-M2b, and Exo-M2c, respectively (Table 2).

3.5. Profile of Differentially Abundant mRNAs. Based on a threshold set at a fold change of $>2$ and $P<0.05$ for the microarray data, a total of 601,171 , and 501 differentially abundant mRNAs were identified in Exo-M2b vs. Exo-M2a, Exo-M2c vs. Exo-M2a, and Exo-M2c vs. Exo-M2b, respectively. Volcano plots were drawn to illustrate the variance in abundance at different $Q$ values (corrected $P$ value via false discovery rate (FDR) estimation) and fold changes (Figure 3). 


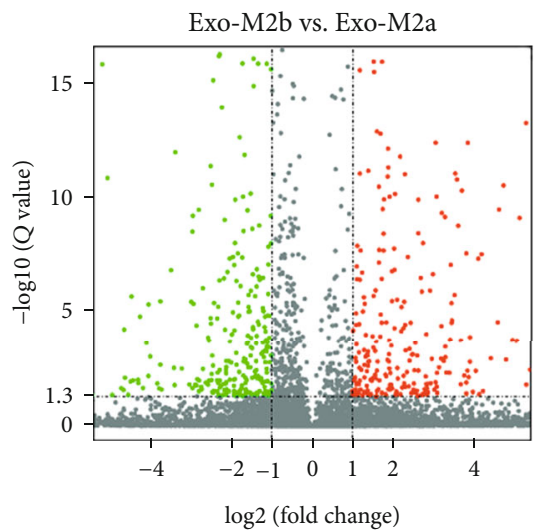

- Gene up:315

- Gene down:286

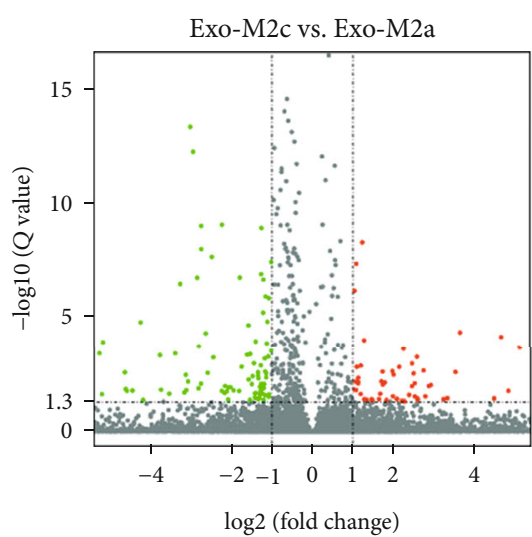

- Gene up:61

- Gene down:110

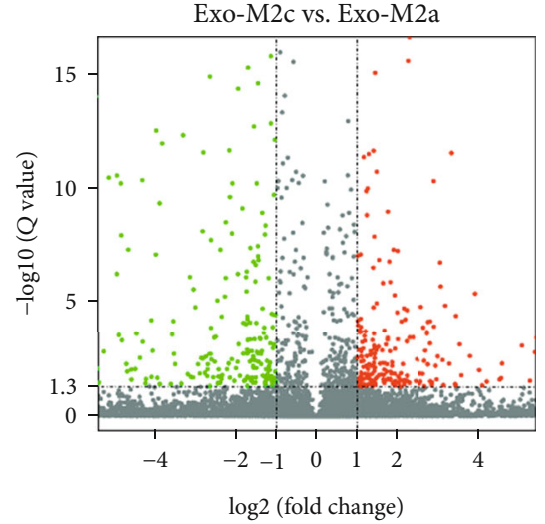

- Gene up:218

- Gene down:284

FIGURE 3: Volcano plot comparing the levels of mRNA abundance between groups. Red and green dots represent upregulated and downregulated mRNAs $(>2.0$-fold change and $P<0.05)$, respectively.

The top 30 differentially abundant mRNAs in the exosomes between groups are presented in Table 3.

3.6. Functional Analyses of mRNAs in the Exosomes. Given that exosomes contain full-length mRNAs that may be translated to affect biological processes in recipient cells, a Kyoto Encyclopedia of Genes and Genomes (KEGG) pathway enrichment analysis was performed and GO analysis was employed to obtain insight into the potential biological functions of the differentially abundant mRNAs. The mRNAassociated molecules were functionally annotated and characterized, and the higher-level functions were represented by networks of molecular interactions, reactions, and associations, that is, the biological pathways. The major pathways identified by KEGG are presented in Figure 4. KEGG pathway analysis suggested that the different mRNAs between Exo-M2a and Exo-M2b involved in the "Toll-like receptor (TLR) signaling pathway," "tumor necrosis factor (TNF) signaling pathway," "NOD-like receptor (NLR) signaling pathway," "NF-kappa B (NF- $\kappa \mathrm{B})$ signaling pathway," and "cytosolic DNA-sensing pathway" were enriched. The different mRNAs between Exo-M2b and Exo-M2c were also involved in the first four pathways listed above. Therefore, the exosomes from $\mathrm{M}_{2 \mathrm{~b}}$ Фs may affect these pathways in recipient cells differently from the exosomes from $\mathrm{M}_{2 \mathrm{a}} \Phi s$ and $\mathrm{M}_{2 \mathrm{c}} \Phi s$. The different mRNAs between Exo-M2a and Exo-M2c were too disperse to exhibit any involvement in pathways, as indicated by small gene numbers and enrichment factors of pathways. GO analysis identified terms in three categories: biological process, cellular component, and molecular function. According to GO analysis, thousands of GO terms were significantly enriched for different mRNAs among all of the groups, based on thresholds of $P<0.05$ and FDR $<0.05$. The main GO categories are presented in Figure 5.

3.7. Profile of $m R N A$ s Involved in the Inflammatory Response. The inflammation-associated mRNA profile of the exosomes from the three $M_{2} \Phi$ subtypes was compared (Figure 6). The ratios presented in the figure were determined by comparing the mRNA profiles of the exosomes from undifferentiated macrophages. The results suggested that numerous transcripts encoding cytokines and chemokines had much higher expression in only the $\mathrm{M}_{2 \mathrm{~b}} \Phi$ population compared with those in the other two populations. Furthermore, the transcript of CCL22 was most abundant in the exosomes from $\mathrm{M}_{2 \mathrm{a}}$ Фs. Taken together, these results indicated that exosomes from different populations expressed numerous unique inflammation-associated mRNA transcripts that equip them for specialized local functions.

\section{Discussion}

In the present study, transcriptome analysis of the exosomes from three of $\mathrm{M}_{2} \Phi$ subtypes was performed, focusing on the mRNA profiles. The abundant mRNAs in each subtype and the different mRNAs between subtypes were examined in detail. In general, the present analysis revealed that exosomes contain various mRNAs and have distinct features. The majority of the top 30 abundant mRNAs were identical among the three subtypes. Furthermore, cluster analysis of mRNAs involved in the inflammatory response and bioinformatics analysis demonstrated that the mRNA profile of ExoM2b was quite different from that of the other two types of exosomes, which is consistent with their different cytological characteristics.

MФs are able to be activated in response to the stimulus they sense, which allows them to combat pathogens, mediate inflammatory reactions, and heal tissue damage in hypersensitivity reactions. In the recent decade, a classification has been developed that describes the complex mechanism of $\mathrm{M} \Phi$ activation as a polarization towards two opposite states, $\mathrm{M}_{1} \Phi$ and $\mathrm{M}_{2} \Phi$ [28]. $\mathrm{M}_{1} \Phi$, or classically activated $\mathrm{M} \Phi$ s, are characterized by inflammatory cytokine secretion and nitric oxide (NO) production, resulting in an effective pathogen killing mechanism [29]. $\mathrm{M}_{2} \Phi s$, or alternatively activated $\mathrm{M} \Phi$ s, widely act as anti-inflammatory, proresolving, wound-healing, and trophic or regulatory 
TABLE 3: Top 30 different abundant mRNAs in exosomes between groups.

\begin{tabular}{|c|c|c|c|c|c|}
\hline \multicolumn{2}{|c|}{ Exo-M2b vs. Exo-M2a } & \multicolumn{2}{|c|}{ Exo-M2a vs. Exo-M2c } & \multicolumn{2}{|c|}{ Exo-M2b vs. Exo-M2c } \\
\hline Gene & $\log 2(\mathrm{FC})$ & Gene & $\log 2(\mathrm{FC})$ & Gene & $\log 2(\mathrm{FC})$ \\
\hline \multicolumn{6}{|l|}{ Upregulation } \\
\hline LOC689205 & 9.67 & Ccl24 & 8.48 & LOC102550257 & 8.76 \\
\hline$I l 12 a$ & 7.81 & $\mathrm{Hba2}$ & 8.46 & Ccl20 & 8.62 \\
\hline LOC103690054 & 7.25 & F7 & 8.43 & F10 & 8.46 \\
\hline $\mathrm{Cxcl} 2$ & 7.23 & Fbp1 & 8.22 & $M m p 3$ & 8 \\
\hline Ppap2c & 7.22 & $M a o b$ & 7.97 & Cpxm1 & 7.51 \\
\hline Htra1 & 7.15 & Prm2 & 7.91 & Cxcl6 & 7.29 \\
\hline Gcnt2 & 7.08 & Plet1 & 7.3 & Ptges & 7.08 \\
\hline $\operatorname{Csf2}$ & 6.95 & Ccl17 & 7.1 & $M m p 13$ & 7.07 \\
\hline Ch25h & 6.89 & $W f_{s} 1$ & 6.98 & Mri1 & 7.01 \\
\hline LOC100359515 & 6.85 & RGD1308147 & 6.97 & $\operatorname{Csf2}$ & 6.96 \\
\hline Scin & 6.81 & Illr 2 & 6.9 & Tut1 & 6.95 \\
\hline LOC102550257 & 6.75 & Mri1 & 6.83 & Adora $2 a$ & 6.93 \\
\hline Gpr84 & 6.74 & Ptrf & 6.77 & Cited4 & 6.84 \\
\hline Cpxm1 & 6.65 & Uchl3-ps1 & 6.54 & Il12a & 6.82 \\
\hline Downregulation & & $\mathrm{Ccl} 22$ & 6.13 & Scin & 6.82 \\
\hline Maob & -9.53 & Socs 1 & 5.57 & Gpr84 & 6.76 \\
\hline Fam57b & -9.05 & Timd2 & 5.26 & Il10 & 6.73 \\
\hline Gpr183 & -8.75 & Trmt6 & 5.19 & Illa & 6.69 \\
\hline Timd2 & -7.91 & Slamf1 & 5.17 & F3 & 6.68 \\
\hline Acsl3 & -7.83 & Ebna1bp2 & 4.63 & $C s f 3$ & 6.6 \\
\hline Ap1s3 & -7.67 & LOC102556076 & 4.61 & Nupr1 & 6.58 \\
\hline Ccl22 & -7.67 & \multicolumn{2}{|c|}{ Downregulation } & $C d 69$ & 6.55 \\
\hline Mylk3 & -7.52 & Pxmp2 & -7.57 & RGD1308147 & 6.51 \\
\hline Tnfaip8l3 & -7.51 & Decr2 & -6.68 & Cxcl1 & 6.49 \\
\hline$F b p 1$ & -7.45 & Tma7 & -6.42 & \multicolumn{2}{|c|}{ Downregulation } \\
\hline Amical & -7.29 & $C c d c 82$ & -6.18 & Decr2 & -8.26 \\
\hline Pet112l & -7.14 & LOC100911372 & -5.44 & Samhd1 & -7.48 \\
\hline Plet 1 & -6.96 & LOC102552889 & -5.13 & Chn2 & -7.47 \\
\hline LOC102556076 & -6.86 & $R a b 33 b$ & -4.85 & LOC102552889 & -7.16 \\
\hline$N p w$ & -6.74 & LOC100910130 & -4.69 & Pet112l & -6.50 \\
\hline
\end{tabular}

$\log 2$ (FC): $\log 2$ (fold change); positive numbers: upregulation; negative numbers: downregulation.

macrophages [30]. Based on the applied stimuli and the achieved transcriptional changes, $\mathrm{M}_{2} \Phi$ s are classified into the $\mathrm{M}_{2 \mathrm{a}} \Phi, \mathrm{M}_{2 \mathrm{~b}} \Phi$, and $\mathrm{M}_{2 \mathrm{c}} \Phi$ subtypes. However, the current classification of the $\mathrm{M}_{2} \Phi$ emphasizes the activation stimuli, rather than the functions [16]. These three subtypes have distinctly different functions in pathophysiological processes.

Prior studies of $\mathrm{M}_{2 \mathrm{~b}} \Phi s$ in heart injury and fibrosis by our group reported that they were distinctly different from $\mathrm{M}_{2 \mathrm{a}}$ Фs and $\mathrm{M}_{2 \mathrm{c}} \Phi \mathrm{s}[19,31] . \mathrm{M}_{2 \mathrm{~b}}$ Фs maintained a balance between anti- and proinflammatory functions, which indicated that they were regulatory $\mathrm{M} \Phi$ s and were consistent with the findings of Mosser et al. [14, 17]. The impact of the $M_{2} \Phi$ subtypes, culture supernatants, and exosomes on the activation of cardiac fibroblasts (CFs) was further studied in vitro. The results indicated that $\mathrm{M}_{2 \mathrm{a}} \Phi s$ and $\mathrm{M}_{2 \mathrm{c}} \Phi s$ promoted the activation of CFs, while $M_{2 b} \Phi$ s showed the opposite effect. Furthermore, the culture supernatants and exosomes showed the same effects as their source cells (Figure S1). These results demonstrated that the exosomes contained important messages from macrophages and transmitted them to downstream cells. Molecules and pathways associated with cardiac fibrosis, including TNF, IL-1, IL-10, TGF family, and platelet-derived growth factors (PDGFs), were might be involved. Therefore, the present study revealed several novel features of the exosomes from $\mathrm{M}_{2} \Phi$ subtypes by focusing on the mRNA profiles.

Several mRNAs encoding cytokines and chemokines, namely, Il1b, CCL2, CCL7, CCL3, and Pf4, were abundant in $\mathrm{M}_{2 \mathrm{~b}} \Phi$ exosomes. The same observation was made in the cluster analysis of genes involved in the inflammatory response, in which $\mathrm{M}_{2 \mathrm{~b}} \Phi$ exosomes contained more transcripts associated with proinflammatory cytokines, chemokines, and regulation factors than $\mathrm{M}_{2 \mathrm{a}} \Phi$ and $\mathrm{M}_{2 \mathrm{c}} \Phi$ exosomes. This characteristic was also reported in $\mathrm{M}_{2 \mathrm{~b}} \Phi \mathrm{s}$, 

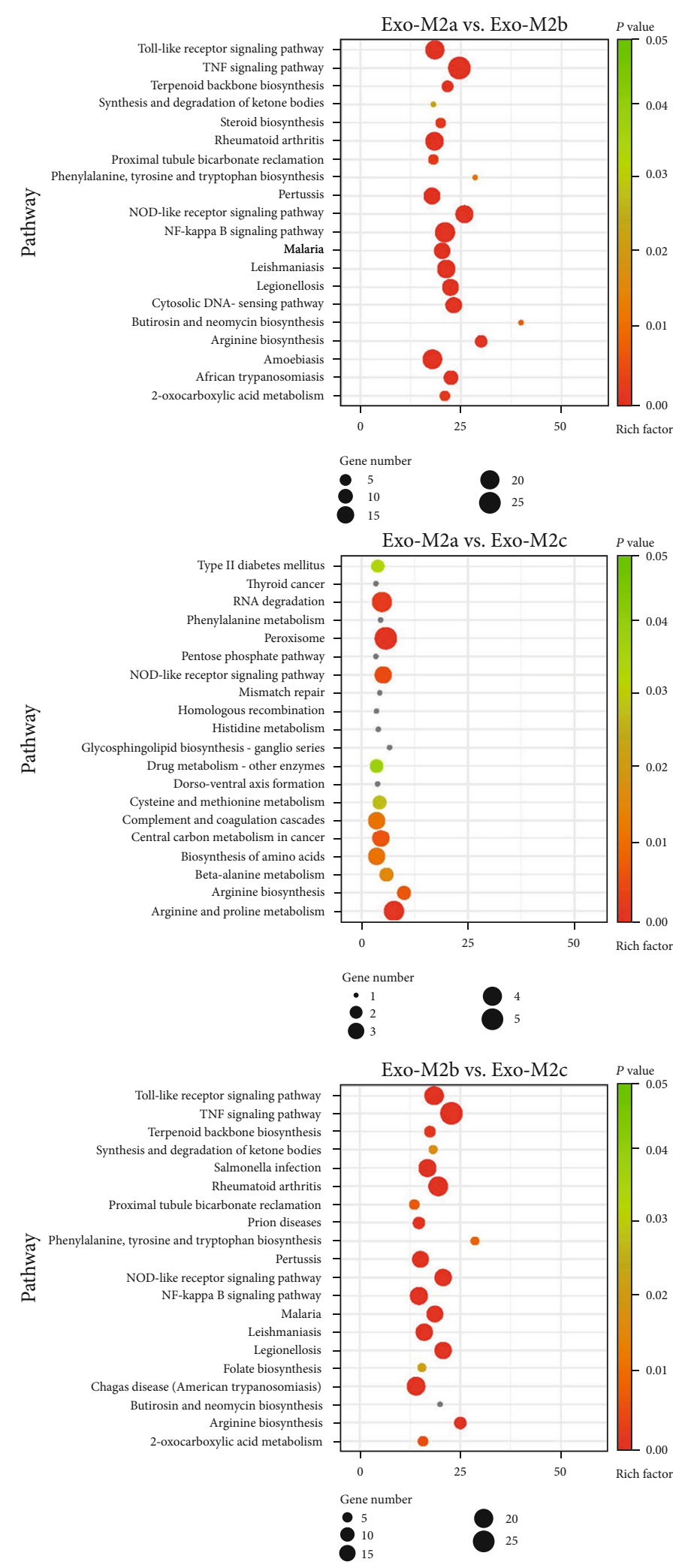

FIGURE 4: KEGG pathway analysis of the differentially abundant mRNAs between groups. The size of the circles indicates the number of genes involved in the pathway, and the color of the circles represents the $P$ value. The threshold for the analysis was set to $P<0.05$ and FDR $<0.05$. KEGG: Kyoto of Encyclopedia of Genes and Genomes; FDR: false discovery rate. 

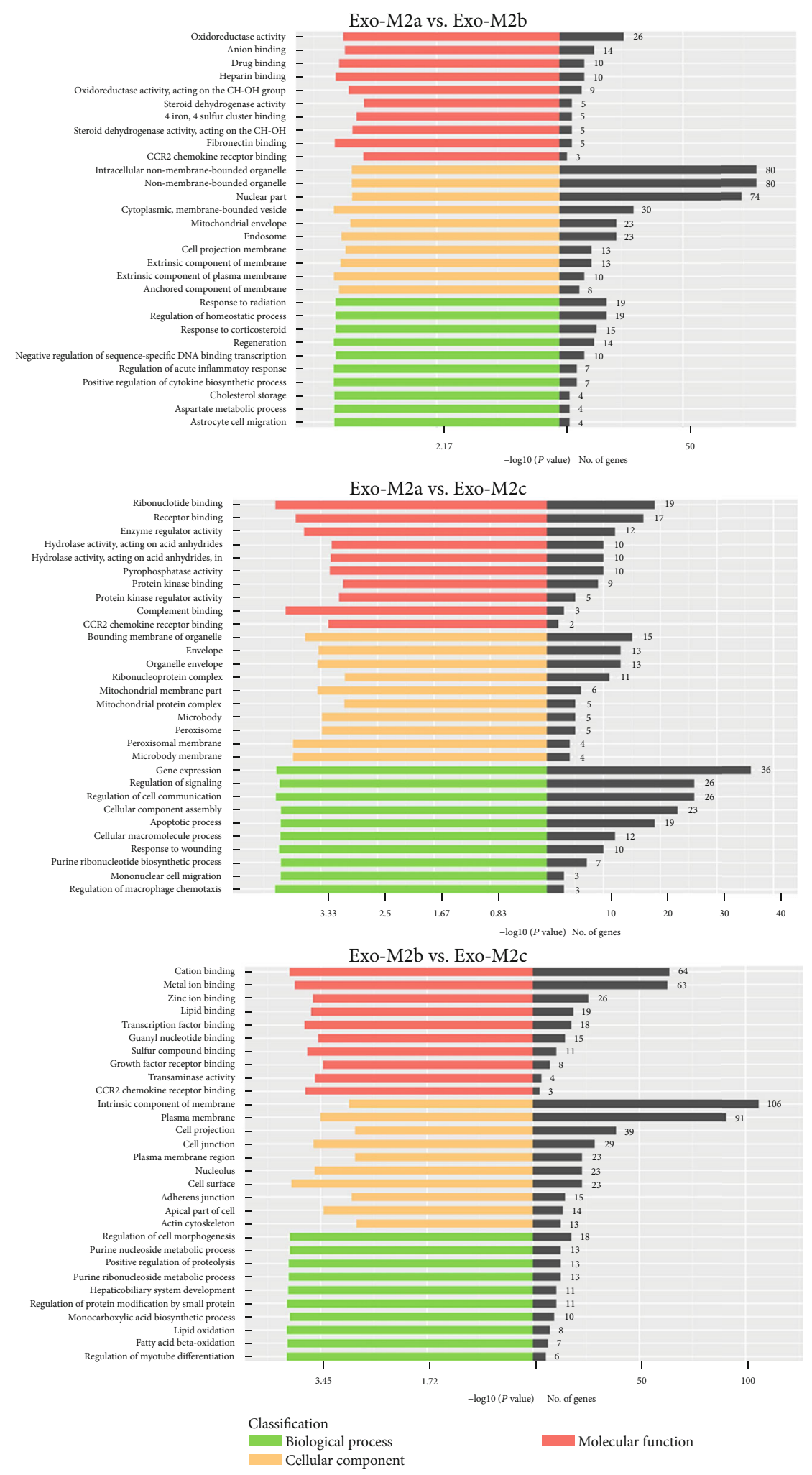

FIGURE 5: GO analysis of the differentially abundant mRNAs between groups. Bar graphs indicate the number of genes that belong to the category. The threshold for the analysis was set to $P<0.05$ and FDR $<0.05$. GO: Gene Ontology; FDR: false discovery rate.

which were indicated to maintain a high level of proinflammatory cytokine production compared with $\mathrm{M}_{2 \mathrm{a}}$ Фs and $\mathrm{M}_{2 \mathrm{c}}$ Фs [32]. While CCL17, CCL22, and CCL24 were excep- tions in the inflammatory gene profile, they were more abundant in $\mathrm{M}_{2 \mathrm{a}} \Phi$ exosomes. This result was also consistent with the cytological characteristics of $\mathrm{M}_{2 \mathrm{a}} \Phi s[32,33]$. These 


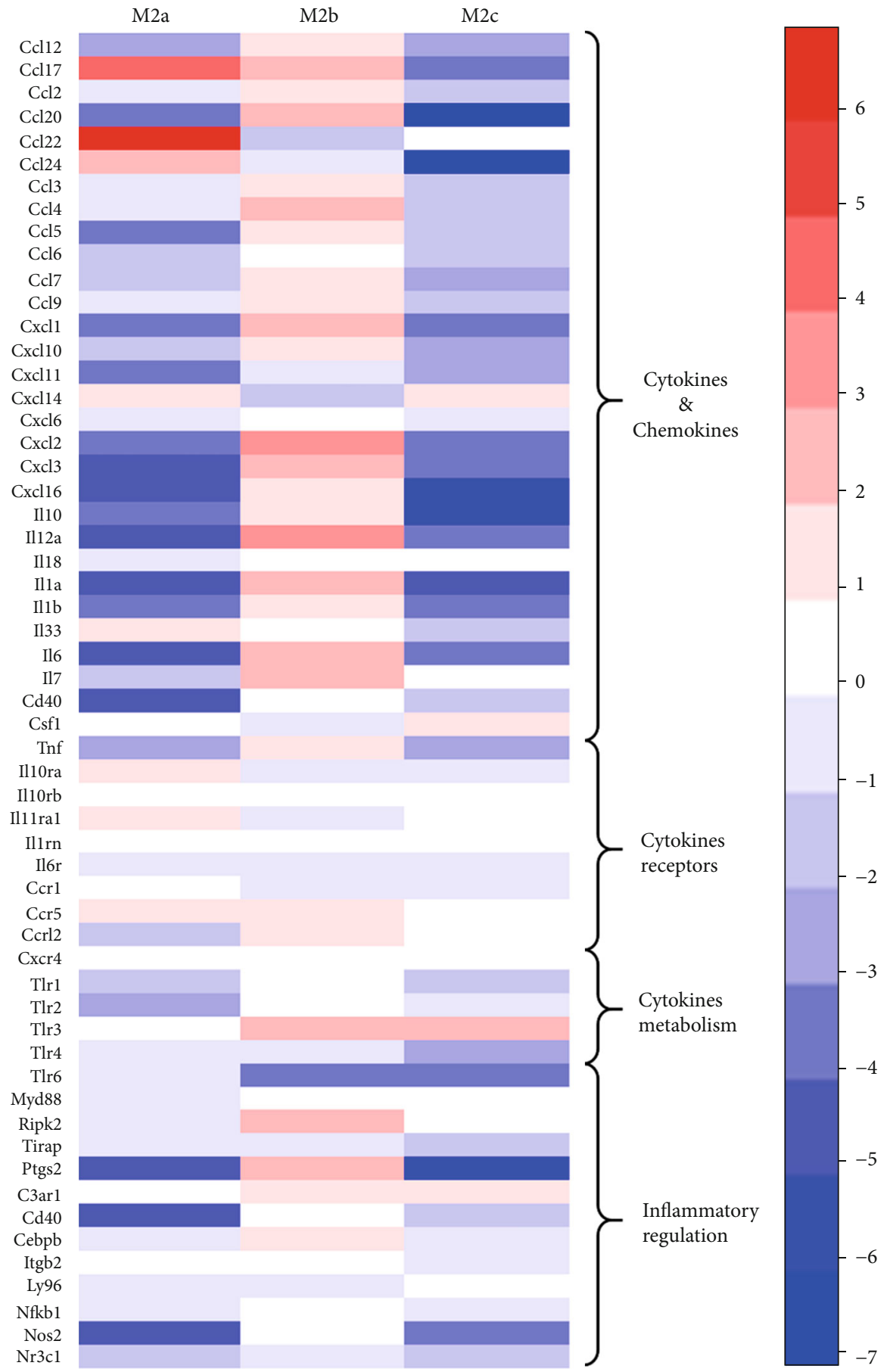

FiguRE 6: Cluster analysis of the inflammation-associated mRNA profile of the exosomes from the three $\mathrm{M}_{2} \Phi$ subtypes. The ratios presented in this figure were determined by comparison to the mRNA expression of the exosomes from BMDMs. Each column represents the indicated sample; each row indicates a significant fold change in mRNA. Upregulated and downregulated genes are indicated in red and blue, respectively. BMDM: bone marrow-derived macrophages.

factors are engaged in numerous pathophysiological processes, including the interface of immunity, tissue homeostasis, and metabolism, and are an important part of the functional specificity of MФ subtypes. The results indicated that exosomes contain certain genes from their source cells and maintain consistent expression in the cytoplasm. Although further studies are required to determine whether the transferred mRNAs are translated into proteins in recipient cells, the present results indicated that exosomes may be involved in the biological actions of MФs.

In the functional analysis, $m R N A$ s detected in $\mathrm{M}_{2 \mathrm{~b}} \Phi$ exosomes were predicted to affect biological pathways, including the TLR, TNF, NLR, and NF- $\kappa$ B signaling pathways, in recipient cells. The TLR and NLR signaling pathways are widely 
involved in innate and adaptive immunity by binding pathogen-associated molecular pattern molecules (PAMPs) and damage-associated molecular pattern molecules (DAMPs) [34, 35]. The TNF signaling pathway governs immune system development, cell survival, and proliferation and regulates metabolic processes [36]. In addition, as a proinflammatory cytokine, TNF mainly induces apoptosis in target cells as well as proteolytic processes [37]. The activation of the TLR and TNF signaling pathways triggers the release of the transcription factor NF- $\kappa \mathrm{B}$ to the nucleus, finally influencing a broad range of biological processes [38]. Furthermore, the transferred mRNAs in $\mathrm{M}_{2 \mathrm{~b}} \Phi$ exosomes probably participate in autoimmune and infectious diseases, including rheumatoid arthritis, pertussis, malaria, leishmaniasis, legionellosis, amoebiasis, salmonella infection, and Chagas disease. These results are consistent with the results of Mosser et al. on $\mathrm{M}_{2 \mathrm{~b}} \Phi[17,39]$. He considers $\mathrm{M}_{2 \mathrm{~b}} \Phi s$, or regulatory $\mathrm{M} \Phi$ s, to be a category of MФs whose major physiological role is to dampen inflammatory immune responses and prevent immunopathology. In this regard, $\mathrm{M}_{2 \mathrm{~b}}$ Фs are certainly distinct from classically activated $M \Phi s$ and quite different from $M \Phi$ s treated with the type 2 T-helper cell (TH2) cytokines IL-4 or IL-13, the socalled $\mathrm{M}_{2} \Phi$ s.

In summary, in the present study, the mRNA transcriptomes of exosomes from three subtypes of $\mathrm{M}_{2} \Phi$ s were characterized. Bioinformatics analyses demonstrated that the mRNAs contained in the exosomes were mediators of the functions of their source cells. Furthermore, it was proved that $\mathrm{M}_{2 \mathrm{~b}}$ Фs are unique among $\mathrm{M}_{2} \Phi$ s and are distinctly different from $M_{2 a} \Phi s$ and $M_{2 c} \Phi s$. Regulatory MФs is probably a more appropriate term for this subtype. Further functional investigations based on these results may help to advance the understanding of the physiological roles of exosometransferred mRNAs in $M \Phi$ functions.

There are some limitations of this study. First, though macrophage populations were polarized according to the methods suggested in the guidelines [40], we could not know for sure the purity of each $\mathrm{M}_{2} \Phi$ population by using flow cytometry or immunofluorescent staining. And we did not have completely pure populations for all studies. Part of the reason is that certain cell-surface markers for each population are lacking [40]. An example of problematic marker use is the expression of CD163 as a "marker" for $\mathrm{M}_{2 \mathrm{c}} \Phi$, which has led to interpretive problems because CD163 is also induced in $\mathrm{M}_{2 \mathrm{a}} \Phi$ [16]. Secondly, the functions of the abundant mRNAs in exosomes were concluded by KEGG pathway enrichment analysis based on the overlap of individual molecules and were not accurate and precise enough.

\section{Data Availability}

The data used to support the findings of this study are included within the article.

\section{Conflicts of Interest}

The authors declare that there is no conflict of interest regarding the publication of this paper.

\section{Authors' Contributions}

Yuan Yue, Suiqing Huang, and Zixuan Wu contributed equally to this article.

\section{Acknowledgments}

This work was supported by the National Natural Science Foundation of China (grant nos. 81770319 and 81900294).

\section{Supplementary Materials}

Figure S1 influence of different $\mathrm{M}_{2} \Phi$ subtypes, culture supernatants, and exosomes on cardiac fibroblasts (CFs). CFs were cocultured with MФs (A) or cultured with MФ supernatants (B) or exosomes isolated from $М \Phi$ supernatants (C). The same volume of culture medium was used as a control (NT). The expression of collagen I (green) and $\alpha$-smooth muscle actin ( $\alpha$-SMA) (red) in the CFs was measured by immunocytochemistry (200x). The expression of COL-1 and $\alpha$-SMA was decreased by coculturing with $\mathrm{M}_{2 \mathrm{~b}} \Phi$ s and was increased by coculturing with $\mathrm{M}_{2 \mathrm{a}} \Phi s$ or $\mathrm{M}_{2 \mathrm{c}} \Phi s$. The cell culture supernatants and exosomes showed the same effects as their source cells. (Supplementary Materials)

\section{References}

[1] C. Thery, L. Zitvogel, and S. Amigorena, "Exosomes: composition, biogenesis and function," Nature Reviews. Immunology, vol. 2, no. 8, pp. 569-579, 2002.

[2] N. L. Syn, L. Wang, E. K. Chow, C. T. Lim, and B. C. Goh, "Exosomes in cancer nanomedicine and immunotherapy: prospects and challenges," Trends in Biotechnology, vol. 35, no. 7, pp. 665-676, 2017.

[3] H. Valadi, K. Ekstrom, A. Bossios, M. Sjostrand, J. J. Lee, and J. O. Lotvall, "Exosome-mediated transfer of mRNAs and microRNAs is a novel mechanism of genetic exchange between cells," Nature Cell Biology, vol. 9, no. 6, pp. 654-659, 2007.

[4] A. Yokoi, Y. Yoshioka, Y. Yamamoto et al., "Malignant extracellular vesicles carrying MMP1 mRNA facilitate peritoneal dissemination in ovarian cancer," Nature Communications, vol. 8, no. 1, p. 14470, 2017.

[5] A. Zomer, C. Maynard, F. J. Verweij et al., "In vivo imaging reveals extracellular vesicle-mediated phenocopying of metastatic behavior," Cell, vol. 161, no. 5, pp. 1046-1057, 2015.

[6] E. H. Ooi, A. J. Psaltis, I. J. Witterick, and P.-J. Wormald, "Innate immunity," Otolaryngologic Clinics of North America, vol. 43, no. 3, pp. 473-487, 2010.

[7] T. Dzopalic, B. Bozic-Nedeljkovic, and V. Jurisic, "Function of innate lymphoid cells in the immune-related disorders," Human Cell, vol. 32, no. 3, pp. 231-239, 2019.

[8] A. Shapouri-Moghaddam, S. Mohammadian, H. Vazini et al., "Macrophage plasticity, polarization, and function in health and disease," Journal of Cellular Physiology, vol. 233, no. 9, pp. 6425-6440, 2018.

[9] F. O. Martinez, A. Sica, A. Mantovani, and M. Locati, "Macrophage activation and polarization," Frontiers in Bioscience, vol. 13, no. 13, pp. 453-461, 2008. 
[10] G. Chinetti-Gbaguidi, S. Colin, and B. Staels, "Macrophage subsets in atherosclerosis," Nature Reviews. Cardiology, vol. 12, no. 1, pp. 10-17, 2015.

[11] D. M. Mosser, "The many faces of macrophage activation," Journal of Leukocyte Biology, vol. 73, no. 2, pp. 209-212, 2003.

[12] K. Fujiu, J. Wang, and R. Nagai, "Cardioprotective function of cardiac macrophages," Cardiovascular Research, vol. 102, no. 2, pp. 232-239, 2014.

[13] M. Lech and H. J. Anders, "Macrophages and fibrosis: how resident and infiltrating mononuclear phagocytes orchestrate all phases of tissue injury and repair," Biochimica et Biophysica Acta, vol. 2013, pp. 989-997, 2013.

[14] D. M. Mosser and J. P. Edwards, "Exploring the full spectrum of macrophage activation," Nature Reviews. Immunology, vol. 8, no. 12, pp. 958-969, 2008.

[15] T. A. Wynn and K. M. Vannella, "Macrophages in tissue repair, regeneration, and fibrosis," Immunity, vol. 44, no. 3, pp. 450-462, 2016.

[16] T. Roszer, "Understanding the mysterious M2 macrophage through activation markers and effector mechanisms," Mediators of Inflammation, vol. 2015, Article ID 816460, 16 pages, 2015.

[17] B. D. Fleming and D. M. Mosser, "Regulatory macrophages: setting the threshold for therapy," European Journal of Immunology, vol. 41, no. 9, pp. 2498-2502, 2011.

[18] L. X. Wang, S. X. Zhang, H. J. Wu, X. L. Rong, and J. Guo, "M2b macrophage polarization and its roles in diseases," Journal of Leukocyte Biology, vol. 106, no. 2, pp. 345-358, 2019.

[19] Y. Yue, S. Huang, L. Wang et al., "M2b macrophages regulate cardiac fibroblast activation and alleviate cardiac fibrosis after reperfusion injury," Circulation Journal, vol. 84, no. 4, pp. 626-635, 2020.

[20] X. Yang, J. Liu, Y. Yue et al., "Cloning, expression and characterisation of a type II cystatin from Schistosoma japonicum, which could regulate macrophage activation," Parasitology Research, vol. 113, no. 11, pp. 3985-3992, 2014.

[21] M. Z. Zhang, X. Wang, Y. Wang et al., "IL-4/IL-13-mediated polarization of renal macrophages/dendritic cells to an M2a phenotype is essential for recovery from acute kidney injury," Kidney International, vol. 91, no. 2, pp. 375-386, 2017.

[22] J. W. Graff, A. M. Dickson, G. Clay, A. P. McCaffrey, and M. E. Wilson, "Identifying functional microRNAs in macrophages with polarized phenotypes," The Journal of Biological Chemistry., vol. 287, no. 26, pp. 21816-21825, 2012.

[23] Y. Fujiwara, Y. Hizukuri, K. Yamashiro et al., "Guanylatebinding protein 5 is a marker of interferon- $\gamma$-induced classically activated macrophages," Clinical \& Translational Immunology., vol. 5, no. 11, article e111, 2016.

[24] D. W. Huang, B. T. Sherman, and R. A. Lempicki, "Bioinformatics enrichment tools: paths toward the comprehensive functional analysis of large gene lists," Nucleic Acids Research, vol. 37, pp. 1-13, 2009.

[25] G. Dennis Jr., B. T. Sherman, D. A. Hosack et al., "DAVID: database for annotation, visualization, and integrated discovery," Genome Biology, vol. 4, no. 5, p. P3, 2003.

[26] P. Shannon, A. Markiel, O. Ozier et al., "Cytoscape: a software environment for integrated models of biomolecular interaction networks," Genome Research, vol. 13, no. 11, pp. 24982504, 2003.

[27] G. Bindea, B. Mlecnik, H. Hackl et al., "ClueGO: a Cytoscape plug-in to decipher functionally grouped gene ontology and pathway annotation networks," Bioinformatics, vol. 25, no. 8 , pp. 1091-1093, 2009.

[28] A. Sica and A. Mantovani, "Macrophage plasticity and polarization: in vivo veritas," The Journal of Clinical Investigation, vol. 122, no. 3, pp. 787-795, 2012.

[29] M. Benoit, B. Desnues, and J. L. Mege, "Macrophage polarization in bacterial infections," Journal of Immunology, vol. 181, no. 6, pp. 3733-3739, 2008.

[30] C. J. Ferrante and S. J. Leibovich, "Regulation of macrophage polarization and wound healing," Advances in Wound Care, vol. 1, no. 1, pp. 10-16, 2012.

[31] Y. Yue, X. Yang, K. Feng et al., "M2b macrophages reduce early reperfusion injury after myocardial ischemia in mice: a predominant role of inhibiting apoptosis via A20," International Journal of Cardiology, vol. 245, pp. 228-235, 2017.

[32] A. Mantovani, A. Sica, S. Sozzani, P. Allavena, A. Vecchi, and M. Locati, "The chemokine system in diverse forms of macrophage activation and polarization," Trends in Immunology, vol. 25, no. 12, pp. 677-686, 2004.

[33] L. Jiang, X. Li, Y. Zhang, M. Zhang, Z. Tang, and K. Lv, "Microarray and bioinformatics analyses of gene expression profiles in BALB/c murine macrophage polarization," Molecular Medicine Reports, vol. 16, no. 5, pp. 7382-7390, 2017.

[34] R. R. Lim, M. E. Wieser, R. R. Ganga et al., "NOD-like receptors in the eye: uncovering its role in diabetic retinopathy," International Journal of Molecular Sciences, vol. 21, no. 3, p. 899, 2020.

[35] J. Henderson, S. Bhattacharyya, J. Varga, and S. O'Reilly, "Targeting TLRs and the inflammasome in systemic sclerosis," Pharmacology \& Therapeutics, vol. 192, pp. 163-169, 2018.

[36] J. R. Bradley, “TNF-mediated inflammatory disease," The Journal of Pathology., vol. 214, no. 2, pp. 149-160, 2008.

[37] V. Jurisic, T. Srdic-Rajic, G. Konjevic, G. Bogdanovic, and M. Colic, "TNF- $\alpha$ induced apoptosis is accompanied with rapid CD30 and slower CD45 shedding from K-562 cells," The Journal of Membrane Biology, vol. 239, no. 3, pp. 115122, 2011.

[38] S. Mitchell, J. Vargas, and A. Hoffmann, "Signaling via the $\mathrm{NF} \kappa \mathrm{B}$ system," Wiley Interdisciplinary Reviews. Systems Biology and Medicine, vol. 8, no. 3, pp. 227-241, 2016.

[39] J. S. Gerber and D. M. Mosser, "Reversing lipopolysaccharide toxicity by ligating the macrophage Fc $\gamma$ receptors," Journal of Immunology, vol. 166, no. 11, pp. 6861-6868, 2001.

[40] P. J. Murray, J. E. Allen, S. K. Biswas et al., "Macrophage activation and polarization: nomenclature and experimental guidelines," Immunity, vol. 41, no. 1, pp. 14-20, 2014. 